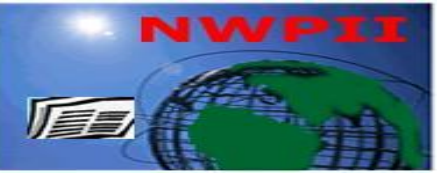

American Journal of Biomedical Sciences

ISSN: 1937-9080

nwpii.com/ajbms

\title{
A Comparative Study in Cervical Muscle Activities during Various Resting Postures Using Electromyography
}

\section{Mehdi Ghalebeigy Poor ${ }^{1}$, Hamidreza Ghasemi Bahraseman ${ }^{2 *}$, Elnaz Pouranbarani ${ }^{1}$, Reza Sarang ${ }^{3}$, Mehdi Shafieian $^{4}$, Karim Leilnahari ${ }^{1}$}

${ }^{1}$ Department of Biomedical Engineering, Science and Research Branch, Islamic Azad University, Tehran, Iran

${ }^{2}$ Mechanical Engineering Department, California State Polytechnic University, Pomona, CA 91768, USA

${ }^{3}$ Control Engineering and Sports Engineering Departments, Faculty of Engineering, Islamic Azad University - Science and Research Branch

${ }^{4}$ Department of Biomedical Engineering, Amirkabir University, Tehran, Iran

"Corresponding Author

Hamidreza Ghasemi Bahraseman

Mechanical Engineering Department

California State Polytechnic University

Pomona, CA 91768

USA

Email: hamid.ghasemi.ipog@gmail.com

Tel: (901) 567-8750

Received: 15 July 2017; | Revised: 23 July 2017; | Accepted: 18 August 2017

\begin{abstract}
Background: Neck and back pain are the most common reported musculoskeletal disorders. Applying surface electromyography to determine muscular activity has been used for a long time for clinical diagnosis. OBJECTIVE: The aim of this study was to assess the effect of two sleeping postures (recommended and preferred postures) on neck muscles activities and fatigue by measuring cervical muscles activities using electromyography. In the recommended posture (Model 1), the cervical and lumbar spine are horizontally aligned, while in the preferred posture (Model 2), the cervical spine is not aligned with lumbar spine. Methods: A total of nine healthy male subjects were asked to side rest with a pillow with adjustable height. The electromyography examinations were performed for upper trapezius (UT) and sternocleidomastoid (SCM) muscles of participants. After acquiring the anthropometric data, participants laid on mattress with medium hardness at the two postures for 30 minutes. Results: Comparison between the two models showed a significant difference $(\mathrm{p}<0.05)$ in the level of electrical activity of neck muscles. In addition, a remarkable difference $(\mathrm{p}<0.05)$ was observed in terms of neck muscle fatigue between the two tested models. Conclusions: The results indicate that the recommended posture developed and tested in this study would reduce the level of fatigue and activity of neck muscles during resting.
\end{abstract}

Keywords: surface electromyography, resting posture, neck muscles activity, neck muscles fatigue, side resting 


\section{Introduction}

Applying surface electromyography (EMG) to determine muscular activities has been used for clinical diagnosis in past decades ${ }^{[1-3]}$. Neck and back pain are the most common among reported musculoskeletal disorders ${ }^{[4,5]}$ and there are studies focused on trapezius and sternocleidomastoid (SCM) muscles ${ }^{[6]}$. Due to the anatomical orientation of back and neck muscles, surface EMG can effectively be utilized to record the muscle activities ${ }^{[7]}$, when compared to more complicated methods such as needle EMG ${ }^{[7-12]}$.

Previous studies have shown that adults prefer side resting $59 \%$ to $73 \%$ of their resting time ${ }^{[13,14]}$. The stiffness of the mattress and its effect on improving the posture of spine were studied by Haex et al. ${ }^{[15]}$ where they used the mattress equipped with air chambers in the region of shoulders, lower back, and pelvis. They found significant differences between male and female subjects. Also it could be obtained that female subjects with a pronounced body contour and male subjects with an athletic body build may not be supported satisfactorily by sleeping systems with a homogeneous stiffness.

Kovacs et al. ${ }^{[16]}$ examined the effects of mattress stiffness on low back pain. They reported that patients who lay on mattresses with normal stiffness experience less pain in their back than the ones with high stiffness mattress. Drinnan et al. ${ }^{[17]}$ characterized the various rest postures and separated them by a difference in parameters determined with electroencephalogram (EEG), electrooculogram (EOG), and electromyogram (EMG) amplitudes. Hansson et al. ${ }^{[6]}$ investigated the root mean square (RMS) of EMG data to present the distribution of various activity levels of neck muscles while at rest. Furthermore, some studies have investigated the relationship between nocturnal trapezius muscle relaxation and neck or shoulder pain for both healthy and unhealthy subjects ${ }^{[18-22]}$. The provided literature review in this field shows a knowledge gap on effects of resting postures and pillow height on people's neck muscles activities and fatigue, and their resting quality. The goal of this paper is to assess the effect of two resting postures on neck muscles activities and fatigues by measuring cervical muscles activities using EMG technique.
The results of this study can lead to an improved resting posture with less muscle activities and fatigue compared to other postures while resting on the sides.

\section{Methods}

A total of nine healthy male subjects (height $=$ $179.27 \pm 7.55 \mathrm{~cm}$, weight $=71.88 \pm 9.26 \mathrm{~kg}$ and age $=$ $21.88 \pm 1.76$ years, Mean \pm SD) were examined in this study. They filled out a questionnaire and were informed about the required instructions. The subjects whose ratio of shoulder width to pelvis was less than $1.45^{[23]}$ were selected for this study. The men whose the proportion of shoulder width (the distance between two deltoid muscles) to their pelvis width is greater than 1.45 are considered as triangular. Those with a proportion less than 1.45 are considered as square. All experiments performed on subjects have been accomplished with regard to the Helsinki declaration ${ }^{[23]}$. This procedure is accepted by medical ethics committee of Kurdistan University of Medical Sciences.

\subsection{Resting Models}

In this study, two side resting models were considered. In both models, subjects were asked to lie on their right lateral sides. For the Model 1 (Fig. 1a), the longitudinal axis/alignment of cervical spine was positioned horizontally by adjusting the pillow height between head and surface of mattress. The spinal alignment was examined using two digital cameras (DCR-TRV356E, Sony Corp, Tokyo, Japan). One camera was distanced $4 \mathrm{~m}$ from the side of the mattress frame at the equal height with the mattress surface. The second camera was positioned on the top of the mattress at $4 \mathrm{~m}$ height. The images of two cameras were concurrently monitored and recorded during the tests. To adjust the pillow height that affects the alignment of cervical spine, the height between the head and mattress were adjusted using polyurethane layers. Using the palpation model ${ }^{[24]}$, the trunk angle and the flexion angle of knee (i.e., the angle between the lateral midline of body trunk and femur bone) were fixed at 135 and 90 degrees, respectively (Fig. 1c). These angles have been reported as recommended 
angles of these limbs for the healthiest resting postures ${ }^{[25]}$.

For the Model 2 testing, participants were asked to simply lie on their right side, without trying to maintain the recommended posture (Fig. 1b). EMG results were recorded for every subject at both models with 30-minute intervals.

The mattress used in this study was comprised of polyurethane layers with height of $5 \mathrm{~cm}$ and density of $25 \mathrm{~kg} \cdot \mathrm{m}-3$ plus a $2 \mathrm{~cm}$ height high resilient (HR) layer. The $\frac{\mathrm{E}}{\mathrm{C}}$ parameter is the stiffness level of mattress where E (N.mm) is the work demanded to compress the core with a maximal force of $450 \mathrm{~N}$, and $\mathrm{C}(\mathrm{N} / \mathrm{mm})$ is the average differential firmness. The $\frac{E}{C}$ value of the tested surface was measured to be $1250 \mathrm{~mm} 2$, which is close to the normal stiffness level of mattress according to the standards provided in the literature ${ }^{[16,26]}$. The E values was obtained by measurement of the total area under the loading curve ranging from 0 to $450 \mathrm{~N}$, and the parameter $\mathrm{C}$ was obtained using the mean slope of loading curve tangents at points of 210, 275 and 340 $\mathrm{N}$ in consistent with the standard method ISO 2430; 2001.

\subsection{EMG Tests}

The EMG electrodes were secured in specific locations using skin tape. Before placing the electrodes, the subjects' skin was cleaned with the alcohol and shaved. The stabilization of the electrodes were done about 10 to 15 minutes and they were tested with an ohmmeter to make sure the electrode skin impedance level was lower than 10 $\mathrm{k} \Omega^{[27-29]}$. The precise locations of electrodes are explained as following:

SCM: Electrodes were located longitudinally along the external part of the muscle ${ }^{[28-31]}$.

UT: electrodes located at $2 \mathrm{~cm}$ away the center point of C4-C5 inter-spinous distance ${ }^{[28-31]}$.

To minimize the probability of overlapping adjacent muscles, for both SCM and UT, the inter electrode distance was considered $20 \mathrm{~mm}$. The common reference electrode was located in the middle of the Spinous portion of the neck.

An eight-channel data acquisition system (Biometrics, Datalog MWX8) was used with band width of 25-500 Hz, sampling rate of $1000 \mathrm{~Hz}$ and the standard $\mathrm{Ag}-\mathrm{AgCl}$ electrode to record $\mathrm{EMG}$ signals. In all tests, the sensitivity of channels was set to $300 \mathrm{mV}$. The amplitude of EMG signals was characterized at 10th (considered a measure of the baseline of muscle activity), 50th (considered a measure of the median of muscle activity) and 90th (considered a measure of the topline of muscle activity) percentiles of the work cycle ${ }^{[7]}$. The following conditions were considered for all tested subjects:

1.Each test was done on a separate day.

2.The subjects did not have any activity before the test.

3.For testing under the Model 1 condition, a digital goniometer was used.

4.During all tests, the environment temperature was kept at around $25^{\circ} \mathrm{C}$.

\subsection{Data management}

For chronological analysis of raw EMG signals, the data was rectified and then averaged before they were filtered in Matlab (Version 7.11) using a second-order Butterworth band pass filter (BPF) which applies cutting frequency ranged from $20 \mathrm{~Hz}$ to $480 \mathrm{~Hz}$. Finally, the RMS of filtered signals was calculated with Matlab. For frequency analysis of raw EMG signals, after rectifying and calculating the average, the median and mean frequencies were collected separately for particular periods.

\section{Results}

As shown in Figure 2, the RMS of whole neck muscle activity in the unit of mv for the Model 1 was significantly lower $(68.5 \%$ on average) than those for the Model 2. At a glance, for all muscles, RMS changes for Model 1, Figure 3A, is much less than those of Model 2, Figure 3B, during the test cycle time. For the former, a general erratic trend with around $20 \%$ of fluctuation was observed for muscles' RMS during test cycle period. However, for the latter, muscles' RMS experienced a downward course around $47 \%$.

Figure 4 demonstrates the comparison between the RMS of data at the 10th and 90th percentiles of the test cycle for both models. The plot shows about 
$67 \%$ less muscle activity in the Model 1 than Model 2. For instance, the Model 2 RMS value for the 90th percentile of the test cycle for the LP is $0.14 \mathrm{mv}$ while it is only $0.025 \mathrm{mv}$ for the Model 1 .

Figures $5 \mathrm{~A}$ and $5 \mathrm{~B}$ show the RMS at the 10th and 90th percentiles of the test cycle for the neck muscles for Models 1 and 2, respectively.

Figure 5 shows the comparison between two percentiles, the first is the 10th and the second is the 90th for both postures. The 10th mean RMS to the 90th mean RMS was reduced on average by $20 \%$ in Model 1 (Figure 5A) as well as increasing remarkably, on average by $47 \%$, in Model 2 $(\mathrm{p}<0.05)$.

For each posture, mean RMS of all muscles were averaged for all subjects and then compared for both postures. As shown in Figure 6, mean RMS of all muscles at the posture 1 is remarkably less than those for the posture 2 .

As shown in Figure 2a, the curves of Median Frequency (MDF) for posture 2 in all the neck's muscles trended to descend (14\%) while posture 1 did not see remarkable change $(3 \%)$ in frequency $(\mathrm{p}<0.02)$.

Both characteristics of the EMG muscle electrical activity and median frequency could be jointly considered as indicators for increasing muscle electrical activity along with decrease in the median frequency and indicating muscle fatigue ${ }^{[32]}$.

The data for all the muscles in the two postures were analyzed by use of SPSS package version 19. The RMS and MDF of muscles signals are considered independent variables. Therefore, the statistical model of one-way ANOVA adjusted by Welch ${ }^{[33]}$ was used for the test. The statistical results show that $F=27.944>3$ after implementing the Welch model and $\mathrm{Fw}=36.71>3$ is significant at the level $\mathrm{p}=0.01<0.05$. The $\mathrm{F}$ value (8.246) for Model 1 and (6.912) for Model 2 are also statistically significant, and they are therefore essential to use post hoc tests connected to heterogeneous variances, similar to Tomhans test. As for the results of post hoc Tomhans test for the two different models, there are significant differences between recommended posture at the level $p=0.01$ and preferred posture at the level of $p$ $=0.05$.
Figure 7 compares and contrasts of means Median Frequency (MDF) of neck muscles from start to the end of test for both models of left and right neck muscles. Unlike the 1-UT case, the 1SCM's RMS result for the right neck muscle is $14.26 \%$ higher than the left muscle's result. In contrast, the right neck muscles' RMS data for both 2-SCM and 2-UT cases are lower than those of left muscles' RMS data; although, this difference is significant (40.59\%) for the 2-UT case's results.

\section{Discussion}

\subsection{Study Findings}

The main goal of the current study is the analysis of the muscle activity index and frequency spectrum in order to understand the muscles fatigue. This method was accomplished by fitting the height of pillow in order to satisfy the Model 1 requirements, especially in cervical zone. This proposes an ideal method for having quality rest and preventing musculoskeletal disorders. The results clearly shows that a reduction in neck's muscle activity from the Model 2 to Model 1 ( $p<0.05$ ).

Also, as shown in Figure 3, less RMS slope for posture 1 than posture 2 shows that Model 1 involves less muscular activities and subsequently muscular fatigue than Model 2. Figure 4 performs the reduction of RMS of posture 1 to posture 2, at the start and end of tests, which results in improvement of muscular activity. The mean RMS for all muscles (left and right upper trapezius and left and right sternocleidomastoid), at the start and end of tests was significantly declined, which proves reduction in muscular demands for model 1 (20\%) (Fig 5). In contrast, for the Model 2, the corresponding value was remarkably increased to $47 \%$ that confirms an increment in muscular demands at the end part of the test as compared with its beginning. Comparing mean RMS for all muscles for all subjects in both models shows that muscular demand was notably larger in the Model 2 than those in Model 1, Figure 6. Considering Figures 3 and 7, although RMS increases by time, frequency is decreased over time and that results in more muscle fatigue in posture 2 than posture 1, which corresponds to the results reported by Lin et al. ${ }^{[32]}$. For SCM and trapezius muscles, the 
increasing EMG amplitude is obtained across period of the sustained cervical contraction. Rise in EMG amplitude while sustained contraction could be ascribed both muscular and neural variations induced by fatigue.

Estimation of SCM's mean frequency (MNF) performs decrease over time in all situations, in agreement with a compression of the EMG spectrum while sustained contraction ${ }^{[34,35]}$. Density spectrum of surface EMG expresses the brief whole action potential distribution that is recorded by EMG. Changing in density spectrum is a symbol of muscle fatigue and shifting toward the less frequency spectrum during the continuous muscle contraction describes the local muscle fatigue ${ }^{[36]}$. Median frequency (MDF) is conventional and essential factors in the investigation of density spectrum ${ }^{[32,37-39]}$ Using compound electromyography signals results from MDF, are preferred over MNF due to involving less error estimation ${ }^{[32]}$. Median and mean frequencies in Model 1 did not have remarkable changes, but Model 2 curve's slope of median frequency over the test remarkably declined, showing the subject's muscle fatigue over the test for the model. Absolute values of the MNF are not well correlated with motor unit recruitment or muscle fiber membrane properties ${ }^{[40,44]}$, hence, variations in absolute values of MNF couldn't be ascribed specified physiological mechanism. In contrast, relative variations in $\mathrm{MNF}$ to time are good indicators of alteration in muscle fiber membrane properties ${ }^{[45]}$.

Also, estimations of SCM and trapezius muscles MNF were decreased by their pain, the behavior of MNF over time was not influenced by pain. The spectral change from maximum to minimum while sustained contraction has been ascribed alteration in the spread of muscle fiber contraction velocity ${ }^{[45-49]}$, motor unit synchronization and motor unit recruitment ${ }^{[50-53]}$. A few studies even reported improved amplitude while dynamic fatiguing contraction ${ }^{[33,44,54]}$. It is well-known that RMS rises with force but with different shapes ${ }^{[55]}$.

\subsection{Limitations and Future Trends}

The test population is limited to young healthy males which are resting. Although taking EMG tests could be difficult due to the large number of neck muscles (more than 20 muscles) that are located relatively close to each other, surface EMG is a common method for cervical muscles [27, 37, 56-60]. This study focused on testing merely healthy subjects while the authors suggest testing subjects with cervical spine problems for future studies. In addition, the ratio of shoulder width to pelvis of lesser than 1.45 were considered for all subjects in this study to eliminate the effects of mattress stiffness. Authors suggest investigation for the shoulder width to pelvis ratio of bigger than 1.45 for future studies.

\section{Conclusion}

Effects of two resting postures on neck muscles' activities and fatigue were studied using electromyography. A mechanism with adjustable pillow height was used to control postures. The electromyography test were performed for UT and SCM muscles of nine healthy male participants. Results showed a noteworthy reduction in the MDF with relatively low intensity dynamic and static contraction (approximately less than 10\% maximum voluntary contraction) during a long time activity. However, the relationship between muscular fatigue and EMG amplitude is vaguer than that of between muscular fatigue and EMG frequency. Furthermore, participants responded to a questionnaire which showed a high level $(100 \%)$ of their satisfaction to Model 1. They believe that Model 1 prevented any musculoskeletal pains that can be created by bad resting postures. 


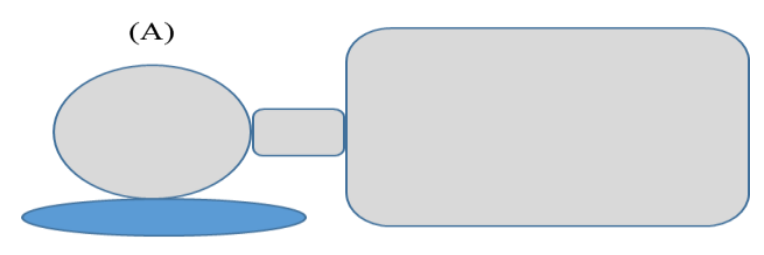

(B)

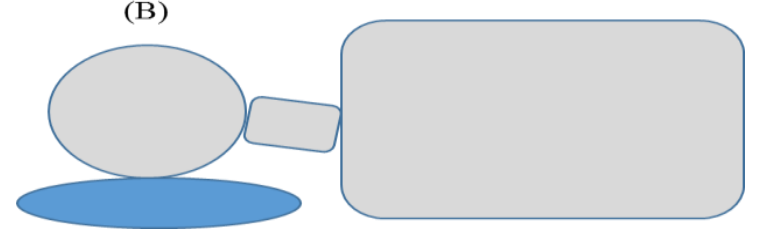

Figure 1 Recommended posture for cervical position (a), preferred posture for cervical position (b).

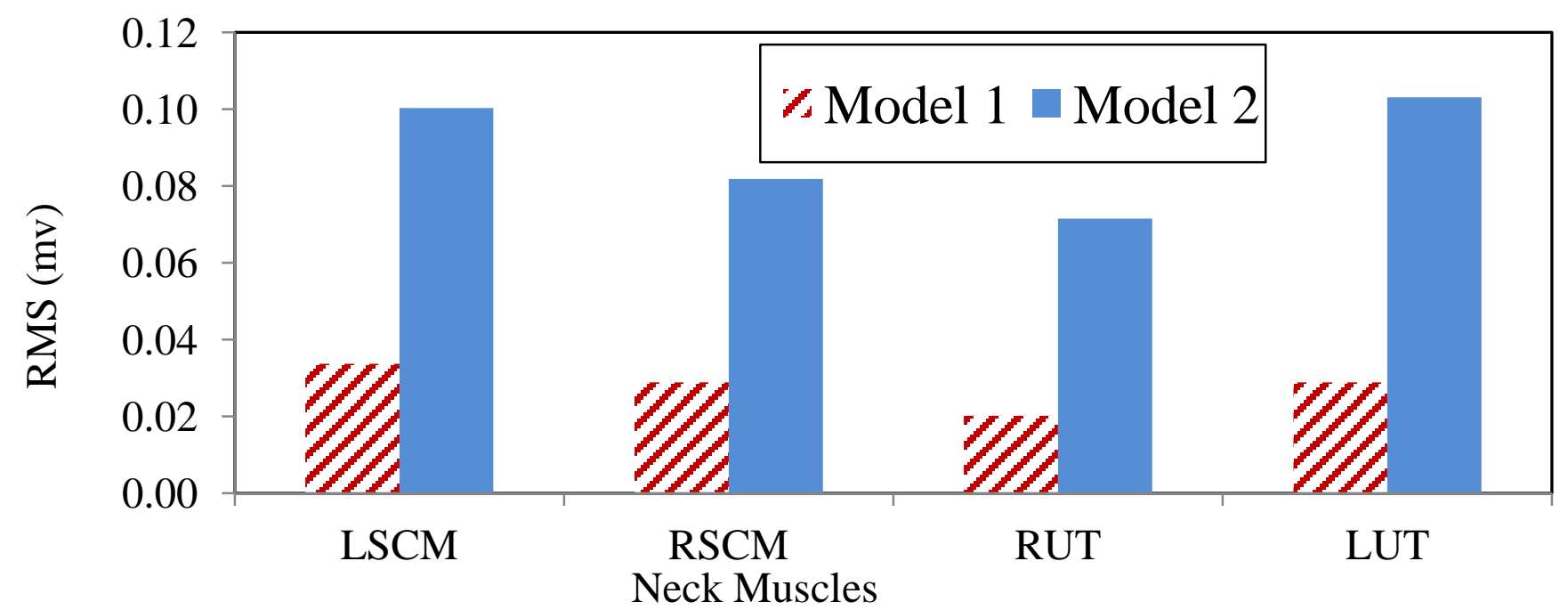

Figure 2 Comparison of the RMS of whole neck muscle activity in two models.

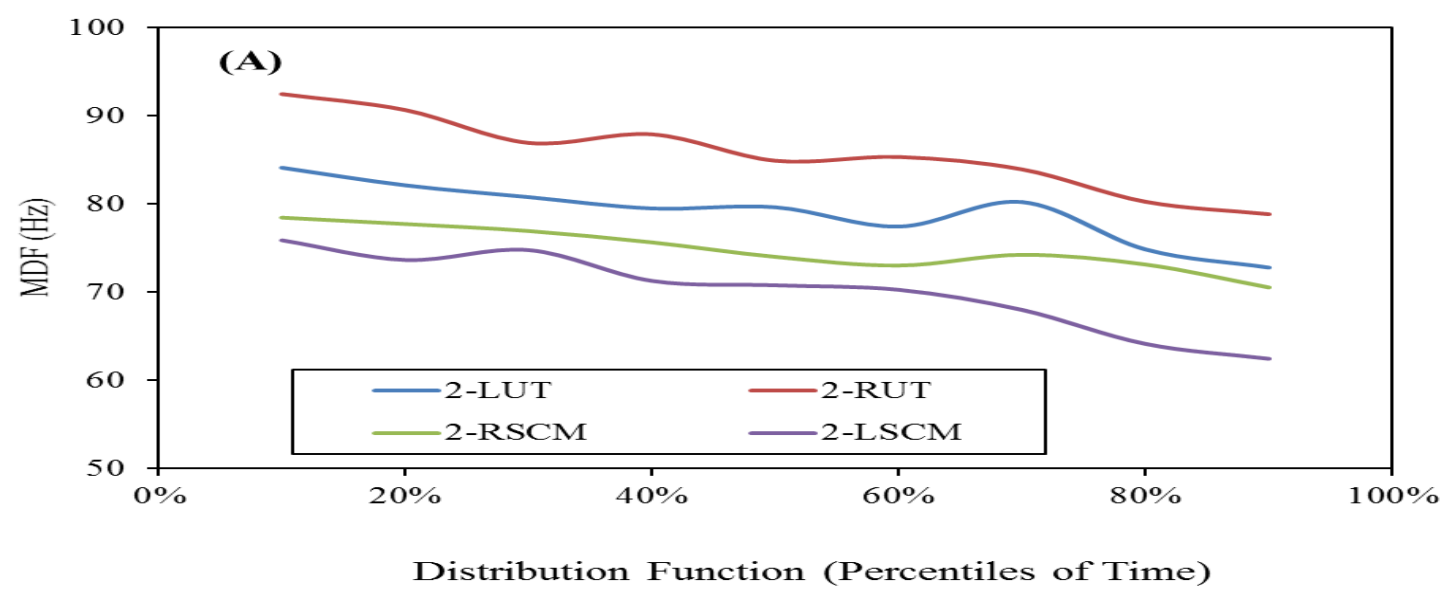




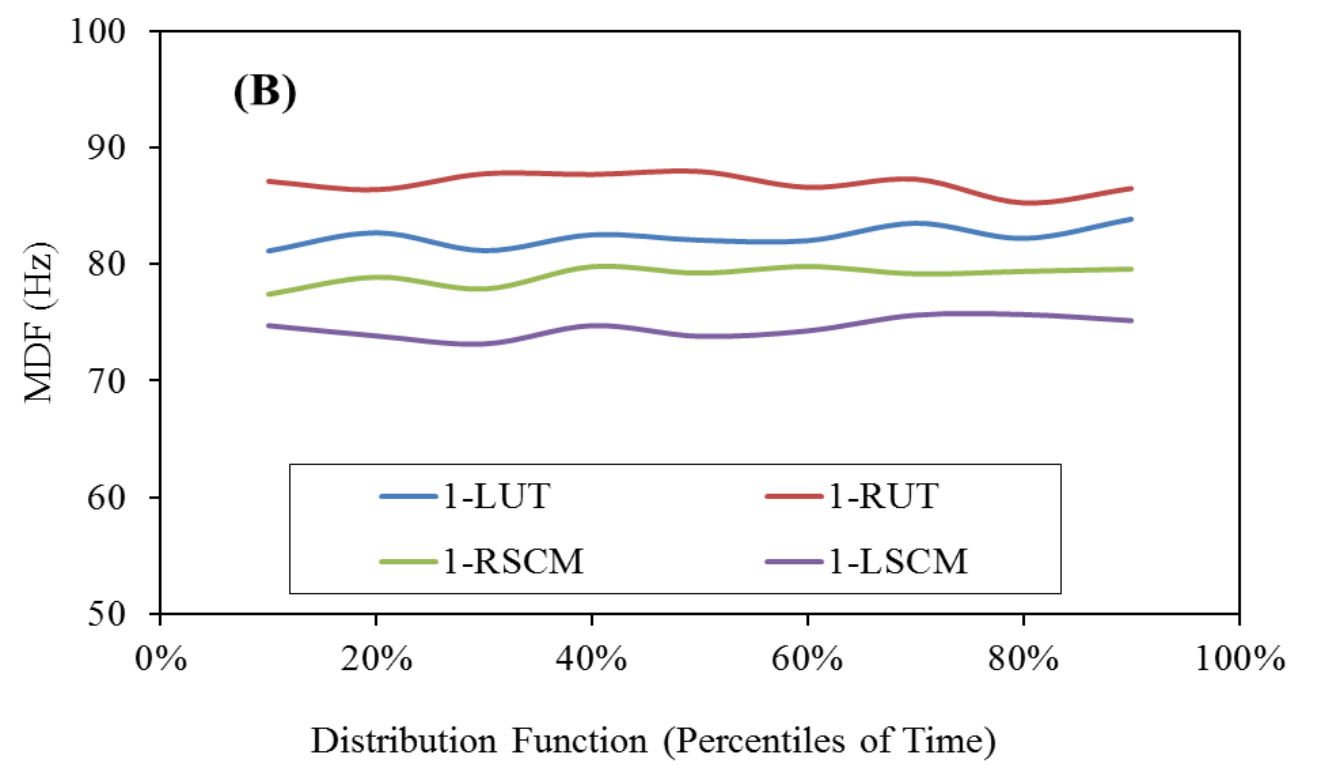

Figure 3 The mean RMS from the start to the end for each muscle of (a) model 2 and model 1 (b) in test cycle time. RSCM: Right sternocleidomastoid

LSCM: Left sternocleidomastoid

RUT: Right upper trapezius

LUT: Left upper trapezius

1-: Model 1

2-: Model 2

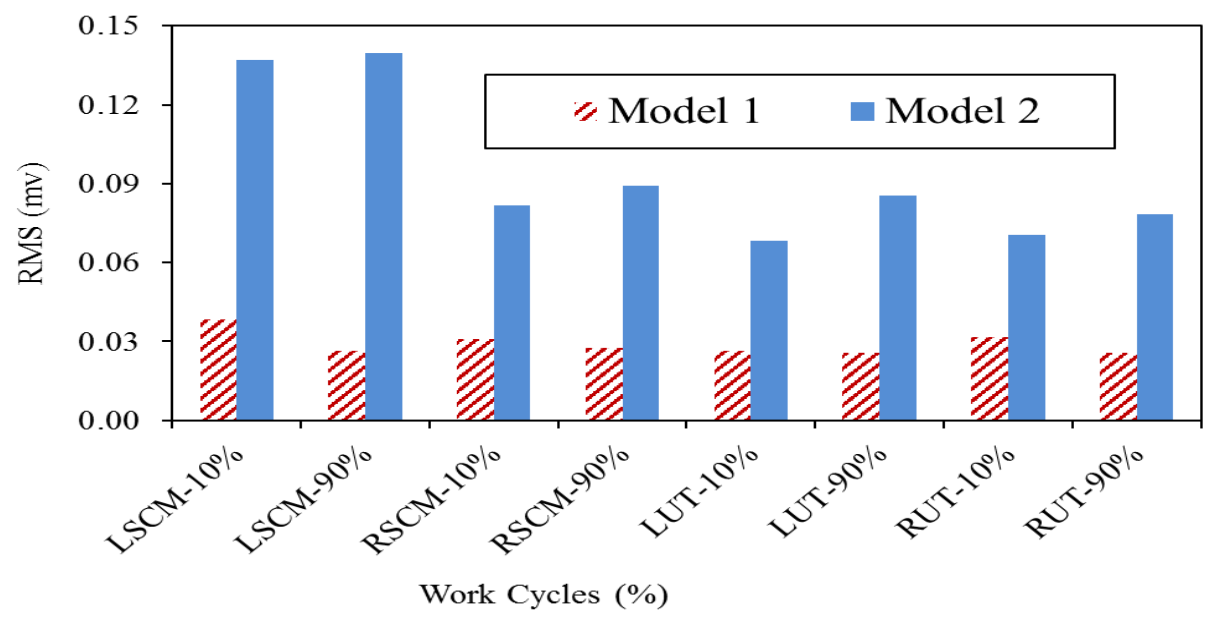

Figure 4 Comparison between the RMS of each muscle at two models for similar percentiles. 

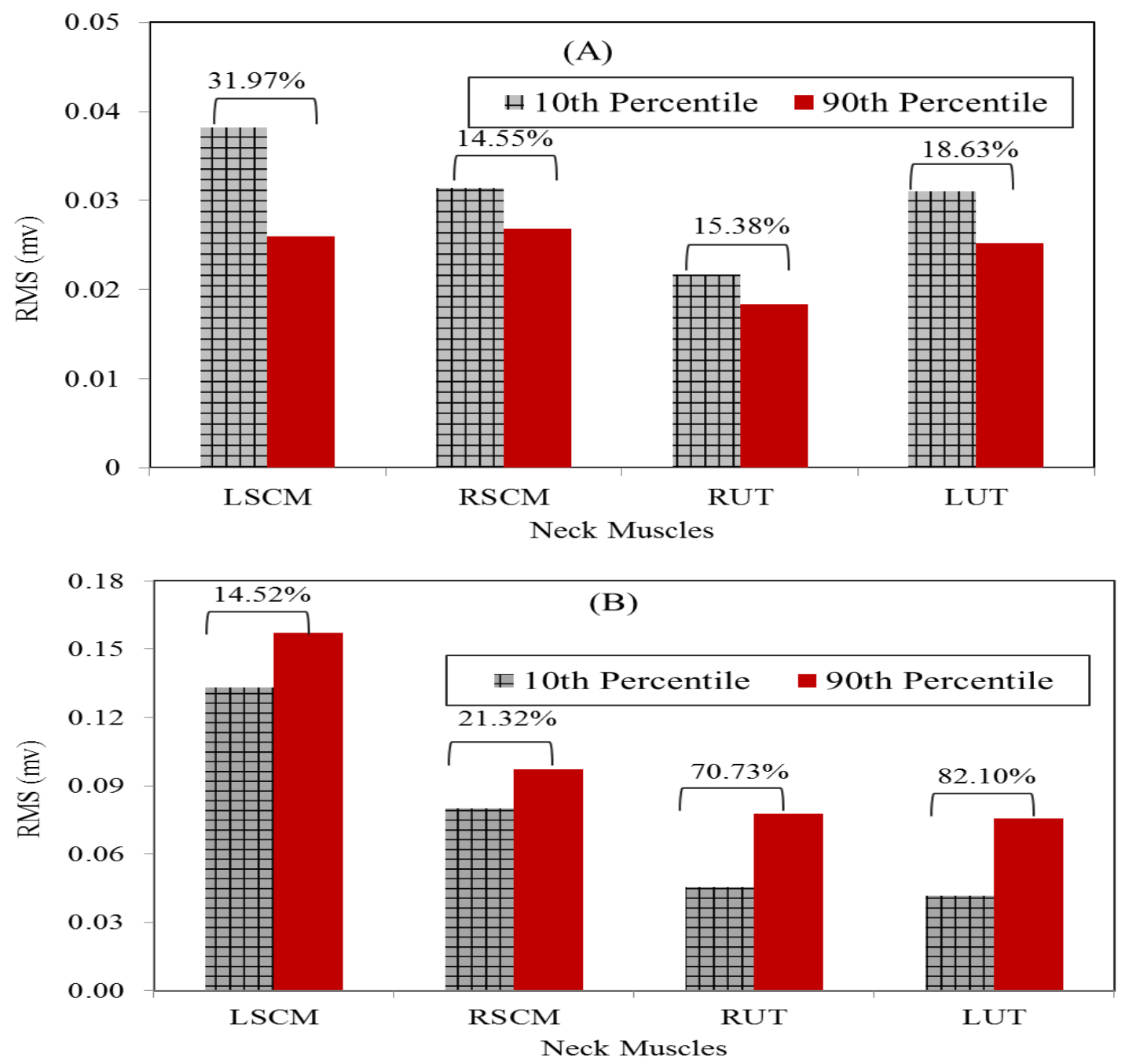

Figure 5 Comparison between the RMS of each muscle at $10^{\text {th }}$ and $90^{\text {th }}$ percentiles for model 1(a) and model 2 (b).

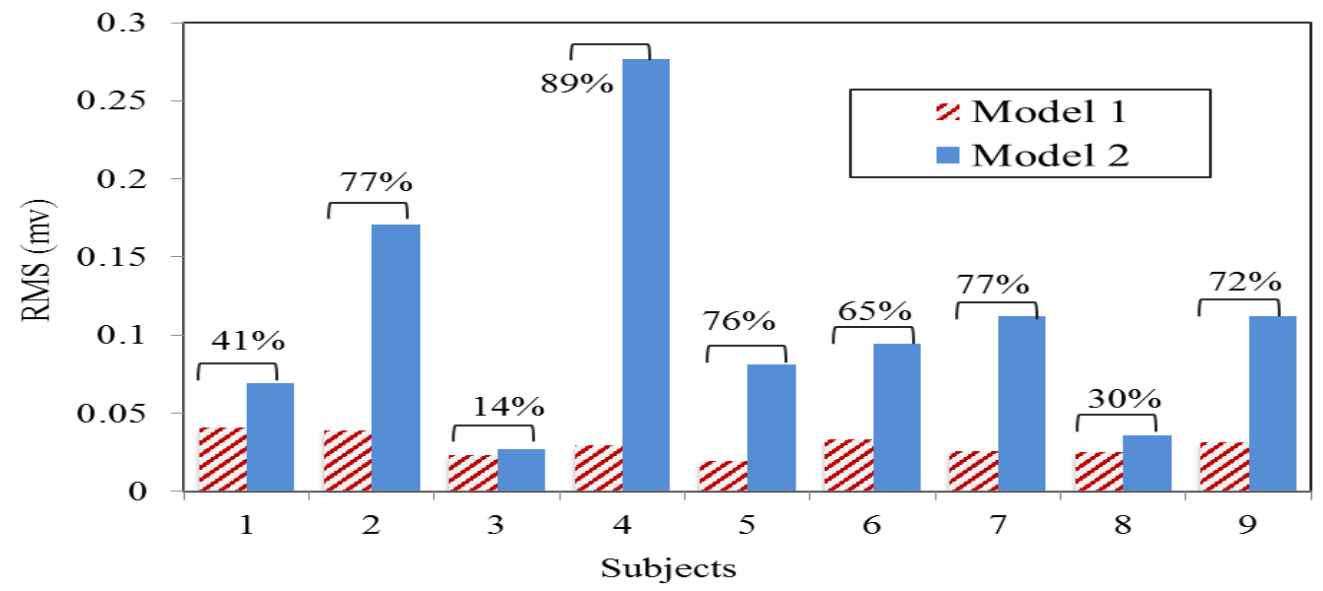

Figure 6 Comparison of the average of mean RMS of all muscles of each subject at two models. 


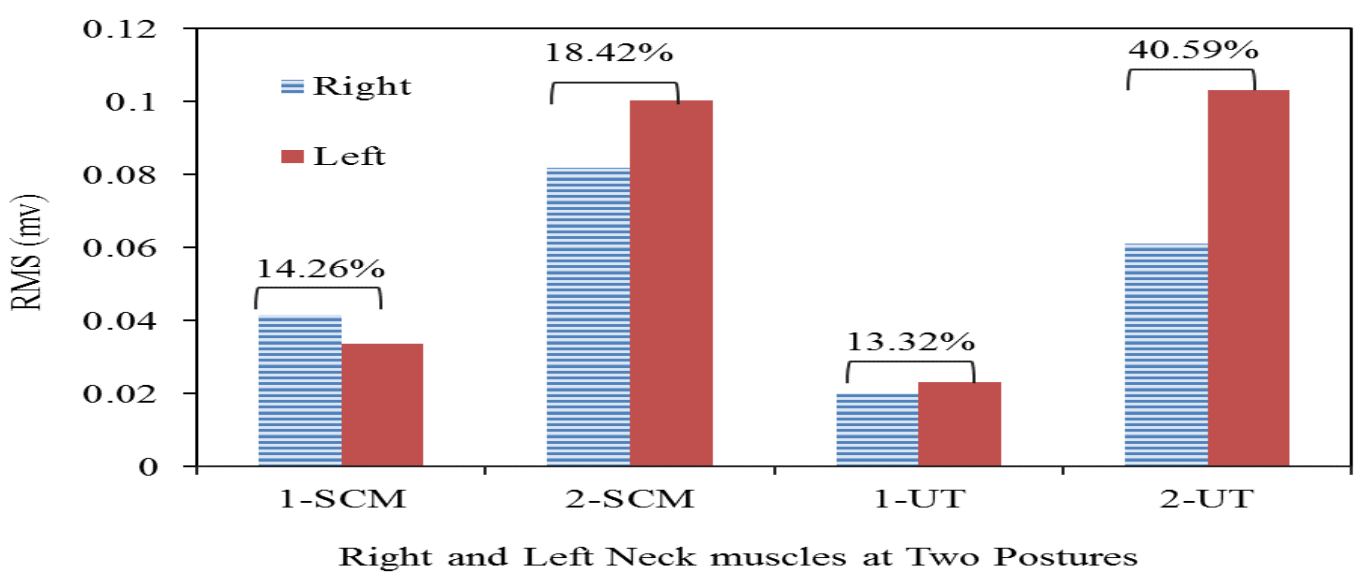

Figure 7 Comparison of means Median Frequency (MDF) of neck muscles from start to the end of test for both models.

SCM: SCM

T: Trapezius

1-: Model 1

2-: Model 2

\section{References}

1. Hermens HJ, Merletti R, Freriks B. European activities on surface electromyography: Proceedings of the first general SENIAM (Surface EMG for Non Invasive Assessment of Muscles) workshop, Torino, Italy; 1996.

2. Hermens HJ, Rau G, Disselhorst-Klug C, Freriks B. Surface electromyography application areas and parameters: Proceedings of the third general SENIAM (Surface EMG for Non Invasive Assessment of Muscles) workshop, May; Aachen, Germany; 1998.

3. Basmajan JV, De Luca CJ. Muscles alive: Their functions revealed by electromyography. Baltimore: Williams and Wilkins; 1985.

4. Strine TW, and Hootman JM. US national prevalence and correlates of low back and neck pain among adults. Arthritis \& Rheumatism. 2007; 57(4): 656. DOI: 10.1002/art.22684

5. Macfarlane GJ, Hunt IM. Predictors of chronic shoulder pain: a population based prospective study. Journal of Rheumatology. 1998; 25(8): 1612.

6. Hansson GA , Asterland P, Skerfving S, Acquisition and analysis of whole-day electromyographic field recordings. In:

Hermens HJ, Ha"gg G, Freriks B, editors.
Proceedings of the second general SENIAM (Surface EMG for Non Invasive Assessment of Muscles) workshop, Sweden: Stockholm; 1997. p.19.

7. Jonsson B. Measurement and evaluation of local muscular strain in the shoulder during constrained work. J Hum Ergol. 1982; 11:73.

8. Linderhed H. A new dimension to amplitude analysis of EMG. Int J Ind Ergon. 1993; 11:243. DOI: 10.1016/0169-8141(93)90112-Q

9. Mathiassen SE, Winkel J. Quantifying variation in physical load using exposure-vstime data. Ergonomics. 1991; 34:1455. DOI: $\underline{10.1080 / 00140139108964889}$

10. Nieminen H, Ha"meenoja S. Quantification of the static load component in muscle work using nonlinear filtering of surface EMG. Ergonomics. 1995; 38:1172. DOI: $\underline{10.1080 / 00140139508925180}$

11. Nordander C, Hansson G-A ${ }^{\circ}$, Asterland P, Balogh I, Bystro"m J,Ohlsson K, Skerfving S. Muscular rest - a measure of physical exposure. In: Proceedings of the 13th trienal congress of International Ergonomic 
Association (IEA' 97), June 29 - July 4;

Tampere, Finland. 1997; 4:207.

12. Veiersted KB, Westgaard RH, Andersen P. Pattern of muscle activity during stereotyped work and its relation to muscle pain. Int Arch Occup Environ Health. 1990; 62:31.

13. Susan J. Gordon, Karen Grimmer-Somers, Patricia Trott. Pillow use: The behaviour of cervical pain, sleep quality and pillow comfort in side sleepers. Mnaual Theraphy. 2009; 14(6):671. DOI: 10.1016/j.math.2009.02.006

14. Susan J Gordon, Karen A Grimmer-Somers, and Patricia $\mathrm{H}$ Trott. A randomized, comparative trial: does pillow type alter cervico-thoracic spinal posture when side lying? .J Multidiscip Healthc. 2011; 4:321. DOI: $10.2147 / \mathrm{JMDH}$. S23028

15. Haex B, Druyts H, Forausberger C, Van Brussel K, Wilde T.D, et al. Sleep comfort: optimization through customization. Journal of biomechanics. 2006; 39:S167. DOI: 10.1016/S0021-9290(06)83583-9

16. Kovacs FM, Abraira V, Peña A, Martín-Rodrí guez JG, et al. Effect of firmness of mattress on chronic non-specific low-back pain: randomised, double-blind, controlled. multicentre trial. Lancet. 2003; 362(9396): 1599. DOI: $10.1016 / \mathrm{S} 0140-6736(03) 14792-7$

17. Drinnan, MJ, Caffarel J, et al. Comparison of manual sleep staging with automated neural network-based analysis in clinical practice. Medical \& Biological Engineering \& Computing. 2006; 44(1 - 2): 105. DOI: $\underline{10.1007 / \mathrm{s} 11517-005-0002-4}$

18. Westgaard, RH, Bonato $\mathrm{P}$, et al. Low-frequency oscillations $(<0.3 \mathrm{~Hz})$ in the electromyographic (EMG) activity of the human trapezius muscle during sleep. Journal of Neurophysiology. 2002; 88(3): 1177.

19. Mork, PJ, Westgaard RH. The association between nocturnal trapezius muscle activity and shoulder and neck pain. European Journal of Applied Physiology. 2004; 92(1-2): 18. DOI: $10.1007 / \mathrm{s} 00421-003-1039-4$

20. Mork, PJ, Westgaard RH. Low - amplitude trapezius activity in work and leisure and the relation to shoulder and neck pain. Journal of Applied Physiology. 2006; 100(4): 1142. DOI: 10.1152/japplphysiol.01111.2005

21. Alsaadi, SM, McAuley JH. Prevalence of sleep disturbance in patients with low back pain. European Spine Journal. 2011; 20(5): 737. DOI: $10.1007 / \mathrm{s} 00586-010-1661-\mathrm{X}$

22. Lobbezoo, F., M. T. Thon, et al. Relationship between sleep, neck muscle activity, and pain in cervical dystonia. Canadian Journal of Neurological Sciences. 1996; 23(4): 285. DOI: 10.1017/S0317167100038233

23. Leilnahari K, Fatouraee N, Khodalotfi M, Sadeghein M.A, Amin Kashani Y. Spine alignment in men during lateral sleep position: experimental study and modeling. Biomed Eng Online. 2011; 10: 103. DOI: 10.1186/1475-925X-10-103

24. Cooperstein R, Haneline MT. Spinous process palpation using the scapular tips as landmark vs a radiographic criterion standard. Journal of Chiropractic Medicine . 2007; 6:87. DOI: 10.1016/j.jcme.2007.07.001

25. Gordon SJ, Grimmer KA, Trott P. Sleep position, age, gender, sleep quality and walking Cervicothoracic symptoms.The internet journal of allied health sciences and $\begin{array}{lll}\text { practice. } & 2007 ; & \text { 5(1):1. }\end{array}$ 10.3138/ptc.2010-13

26. Bert H. Jacobson, Tia Wallace, and Hugh Gemmellb. Subjective rating of perceived back pain, stiffness and sleep quality following introduction of medium-firm bedding systems. J Chiropr Med. 2006; 5(4: 128. DOI: 10.1016/S0899-3467(07)60145-1

27. Joines SM, Sommerich CM, Mirka GA, Wilson JR. Moon SD: Lowlevel exertions of neck musculature: a study of researchmethods. J Electromyogr Kinesiol. 2006;16:485. DOI: 10.1016/j.jelekin.2005.09.007

28. Falla DL, Dall'Alba PT, Rainoldi A, Merletti R. Jull GA: Location of innervation zones of SCM and scalene muscles- a basis for clinical and research electromyography applications. Clin Neurophysiol. 2002; 113:57.

29. Falla DL, Dall'Alba PT, Rainoldi A, Merletti R. Jull GA: Repeatability of surface EMG variables in the SCM and anterior scalene 
muscles. Eur J Appl Physiol. 2002; 87:542. DOI: 10.1007/s00421-002-0661-X

30. Cara E Stepp, James T Heaton, Rebecca N Givens, and Robert E Hillman. Use of neck and face surface electromyography for controlling a prosthetic voice after total laryngectomy. IEEE Trans Neural Syst Rehabil Eng. 2009;Vol. 17(2):146. DOI: 10.1109/TNSRE.2009.2017805

31. Seniam, SENIAM, Surface ElectroMyoGraphy for the Non-Invasive Assessment of Muscles. 2010. Available from: http://www.seniam.org.

32. Lin $M$, Liang $H$, Lin $K$, Hwang $Y$. Electromyographical assessment on muscular fatigue-an elaboration upon repetitive typing activity. Journal of Electromyography and Kinesiology. 2004; 14: 661. DOI: 10.1016/j.jelekin.2004.03.004

33. George Casella. Statistical design. Springer. (2008). ISBN 978-0-387-75965-4.

34. Merletti R, Knaflitz M, De Luca CJ. Myoelectric manifestations of fatigue in voluntary and electrically elicited contractions. J Appl Physiol. 1990;69:1810.

35. Linsen W, Stegman D, Joosten E, van't Hof M, Binkhorst R, Notermans S.Variability and interlationships of surface EMG parameters during local muscle fatigue. Muscle \& Nerve. 1993;16, 849. DOI: 10.1002/mus.880160808

36. Björn $\ddot{A}$. Impaired neck motor function and pronounced pain-related fear in helicopter pilots with neck pain- A clinical approach. Journal of Electromyography and Kinesiology. 2008; 18: 538. DOI: $\underline{\text { 10.1016/j.jelekin.2007.01.002 }}$

37. Roman-Liu D, Konarska M. Characteristics of power spectrum density function of EMG during muscle contraction below 30\% MVC. Journal of Electromyography and Kinesiology. 2009; 19: 864. DOI: 10.1016/j.jelekin.2008.05.002

38. Szeto P.G, Straker L.M, O_Sullivan P.B. EMG median frequency changes in the neck shoulder stabilizers of symptomatic office workers when challenged by different physical stressors. Journal of Electromyography and Kinesiology. 2005; 15: 544. DOI: $\underline{10.1016 / j . j e l e k i n .2005 .06 .004}$
39. Esposito F, Orizio C, Veicsteinas A. Electromyogram and mechanomyogram changes in fresh and fatigued muscle during sustained contraction in men. Eur $\boldsymbol{J}$ Appl Physiol. 1998; 78: 494. DOI: 10.1007/s004210050451

40. Falla DL, Graven-Nielsen T, Farina D. Spatial and temporal changes of UT muscle fiber conduction velocity are not predicted by surface EMG spectral analysis during a dynamic upper limb task. J Neurosci Methods. 2006; $\quad 156(1 \quad$ - 2):236. DOI: 10.1016/j.jneumeth.2006.03.006

41. Farina D, Fosci M, Merletti R. Motor unit recruitment strategies investigated by surface EMG variables. J Appl Physiol. 2002; 92(1):235.

42. Farina D, Merletti R, Enoka RM. The extraction of neural strategies from the surface EMG. J Appl Physiol.2004;96:1486. DOI: 10.1152/japplphysiol.00162.2014

43. Merlo E, Pozzo M, Antonutto G, Merletti R, di Prampero PE, Farina D. Time-frequency analysis and estimation of muscle fiber conduction velocity from surface EMG signals during explosive dynamic contractions. J Neurosci Methods. 2005;142:267. DOI: 10.1016/j.jneumeth.2004.09.002

44. Masuda k, Masuda T, Sadoyama T, Inaki M, Katsuta S. Changes in surface EMG parameters during static and dynamic fatiguing contractions, Journal of Electromyography and Kinesiology. 1999; 9:39.

45. Merletti R, Farina D, Gazzoni M, Schieroni MP. Effect of age on muscle functions investigated with surface electromyography. Muscle Nerve. 2002; 25(1):65.

46. Brody LR, Pollock MT, Roy SH, De Luca CJ, Celli B. pH-induced effects on median frequency and conduction velocity of the myoelectric signal. J Appl Physiol. 1991;71(5):1878.

47. De Luca CJ. Myoelectrical manifestations of localized muscular fatigue in humans. Crit Rev Biomed Eng. 1984;11(4):251.

48. Lindstrom L, Magnusson R, Petersen R. Muscle fatigue and action potential 
conduction velocity changes studied with frequency analysis of EMG signals. Electromyogr Clin Neurophysiol. 1970;10:341.

49. Stulen FB, DeLuca CJ. Frequency parameters of the myoelectric signal as a measure of muscle conduction velocity. IEEE Trans Biomed Eng. 1981;28:515. DOI: 10.1109/TBME.1981.324738

50. Bigland-Ritchie B, Donovan EF, Roussos CS. Conduction velocity and EMG power spectrum changes in fatigue of sustained maximal efforts.J Appl Physiol. 1981;51:1300.

51. Kleine BU, Stegeman D, Mund D, Anders C. Influence of motorneuron firing synchronisation on SEMG characteristics in dependence of electrode position. J Appl Physiol. 2001;91:1588.

52. Stegeman D, Blok J, Hermens H, Roeleveld K. Surface EMG models: properties and applications. J Electromyogr Kinesiol. 2000;10:313.

53. Gazzoni M, Farina D, Merletti R. Motor unit recruitment during constant low force and long duration muscle contractions investigated by surface electromyography. Acta Physiol Pharmacol Bulg. 2001; 26:67.

54. Hagberg M. Muscular endurance and surface electromyogram in isometric and dynamic exercise, Journal of Applied Physiology. 1981; 51:1.
55. Gerdle B, Henriksson-Larsen K, Lorentzon R, Wretling ML. Dependence of the mean power frequency of the electromyogram on muscle force and fibre type. Acta Physiol Scand. 1991;142(4):457. DOI: 10.1111/j.17481716.1991.tb09180.x

56. Kamibayashi L, Richmond F. Morphometry of human neck muscles.Spine. 1998; 23: 1314.

57. Sommerich C.M, Joines S.M.B, Hermans V, Moon S.D. Use of surface electromyography to estimate neck muscle activity. Journal of Electromyography and Kinesiology. 2000; 10: 377.

58. Thuresson M, Björn Ä, Linder J, HarmsRingdahl K. Intra-rater reliability of electromyographic recordings and subjective evaluation of neck muscle fatigue among helicopter pilots. Journal of Electromyography and Kinesiology. 2005; 15: 323. DOI: 10.1016/j.jelekin.2004.11.001

59. Björn $\ddot{A}$. Impaired neck motor function and pronounced pain-related fear in helicopter pilots with neck pain-A clinical approach. Journal of Electromyography and Kinesiology. 2008; 18: 538. DOI: 10.1016/j.jelekin.2007.01.002

60. Kumar S, Mital A. Electromyography in Ergonomics, Taylor and Francis, London; 1996. 